Pacific Journal of Mathematics

SOME HAUSDORFF MEANS WHICH EXHIBIT THE GIBBS 


\title{
SOME HAUSDORFF MEANS WHICH EXHIBIT THE GIBBS' PHENOMENON
}

\author{
Arthur E. Livingston
}

1. Introduction. The regular Hausdorff mean of order $n$ with kernel $g(x)$ for the sequence $\left(s_{k}\right)$ is defined by

$$
h_{n}=h_{n, g}=\sum_{k=0}^{n}\left(\begin{array}{l}
n \\
k
\end{array}\right) s_{k} \int_{0}^{1} t^{k}(1-t)^{n-k} d g(t) \text {, }
$$

where $g(x)$ is of bounded variation on the interval $0 \leq x \leq 1, g(1)-g(0)=1$, and $g(0+)=g(0)$. The integral in the definition being a Stieltjes integral, it is clear that $g(0)$ may be taken to be zero.

For the sequence

$$
s_{n}(x)=\sum_{k=1}^{n} \frac{\sin k x}{k},
$$

Otto Szaśz [3] has proved the following result: If, as $n \rightarrow \infty, x_{n} \rightarrow 0+$ and $n x_{n} \rightarrow A \leq \infty$, then

$$
h_{n, g}\left(x_{n}\right) \rightarrow \int_{0}^{1} \operatorname{Si}(A x) d g(x),
$$

where

$$
\operatorname{Si}(x)=\int_{0}^{x} \frac{\sin t}{t} d t .
$$

He defines the Gibbs' ratio for the kernel $g(x)$ to be

$$
F(g)=\max _{A>0} \frac{2}{\pi} \int_{0}^{1} \operatorname{Si}(A x) d g(x) .
$$

Received March 14, 1952. The work in this paper was done during the period when the author held Atomic Energy Commission Predoctoral Fellowship OR-21478.

Pacific J. Math. 3 (1953), 407-415 
If $F(g)>1$, then the sequence $\left\{h_{n, g}(x)\right\}$ exhibits the Gibbs' phenomenon on the right at $x=0$.

It is here proved that ( 1$)$ if $\alpha(x)$ is a regular Hausdorff step-function kernel whose points of jump are linearly independent over the rationals, then $F(\alpha)>1$; (2) if $\alpha(x)$ is regular and has precisely two jumps, then $F\left(\alpha_{0}\right)>1$. It seems reasonable that the first result is true without the hypothesis of linear independence, but the author has been unable to show this.

The Euler method of summability $(\epsilon, p), 0<p \leq 1$, is a regular Hausdorff method having for its kernel the one-step function $\epsilon_{p}(x)$ which vanishes for $0 \leq x<p$, and has the value one for $p \leq x \leq 1$; the method $(\epsilon, p)$ is ordinarily denoted by $(E,(1-p) / p)$. Clearly,

$$
F\left(\epsilon_{p}\right)=\frac{2}{\pi} \operatorname{Si}(\pi)>1
$$

so that the one-step case of (1) above follows trivially (this was shown by Szász $[2,3])$.

2. Notation. It is convenient to collect here some notations which will be used throughout this paper.

(a) $\alpha(x)$ is a step-function defined as follows:

$$
\begin{array}{rlrl}
\alpha(x) & =a_{1}=0 & & \text { for } 0 \leq x<\beta_{1}, \\
& =a_{k} \quad & \text { for } \beta_{k-1} \leq x<\beta_{k} \text { and } k=2, \cdots, N, \\
& =a_{N+1}=1 \text { for } \beta_{N} \leq x \leq 1,
\end{array}
$$

where $a_{k} \neq a_{k+1}$ for $k=1, \cdots, N$;

(b) $\operatorname{Si}(x)=\int_{0}^{x} \frac{\sin t}{t} d t$;

(c) $\operatorname{si}(x)=\operatorname{Si}(x)-\frac{1}{2} \pi=\int_{\infty}^{x} \frac{\sin t}{t} d t$;

(d) $f(x)=f_{\alpha}(x)=\frac{2}{\pi} \int_{0}^{1} \operatorname{Si}(x y) d \alpha(y)=\frac{2}{\pi} \sum_{k=1}^{N} A_{k} \operatorname{Si}\left(x \beta_{k}\right)$,

where $A_{k}=a_{k+1}-a_{k}$;

(e) $F(\alpha)=\max _{x>0} f_{\alpha}(x)$. 
It is clear that it is no restriction to assume that all regular step-function kernels are of the form (a).

3. The zeros of $\operatorname{si}(x)$. It is well known that $\operatorname{si}[(2 n+1) \pi]>0$ and si $(2 n \pi)<0$ for $n=0,1, \cdots$, and that si $(x)$ has precisely one zero, call it $z_{n}$, in each interval $n \pi<x<(n+1) \pi(n=0,1, \ldots)$. It is intuitively clear and easy to prove rigorously that

$$
z_{n}-\left(n+\frac{1}{2}\right) \pi>0
$$

It will be shown in this section that even more is true, namely, that

$$
z_{n}-\left(n+\frac{1}{2}\right) \pi \downarrow 0
$$

The tables [4] for the sine integral show that

$$
1.9264<z_{0}<1.9265 \text { and } 4.893<z_{1}<4.894 \text {. }
$$

It therefore follows that the following statement is true:

THEOREM 3.1. The function $\mathrm{si}(x)$ is positive whenever

$$
-1.2150<x-(2 n+1) \pi<\frac{1}{2} \pi,
$$

and is negative whenever

$$
x \geq 0 \text { and }-1.389<x-2 n \pi<\frac{1}{2} \pi, \quad(n=0,1, \cdots) .
$$

This result is needed in $\S 5$.

It will now be shown that the zeros modulo $\pi$ of $\operatorname{si}(x)$ form a strictly decreasing sequence with limit $\pi / 2$. The formal statement is:

TheOREM 3.2. Let $\left(n+1 / 2+x_{n}\right) \pi$ be the zero of $\int_{x}^{\infty} u^{-1} \sin u d u$ in the interval

$$
n \pi<x<(n+1) \pi \quad(n=0,1, \ldots) .
$$

Then the sequence $\left(x_{n}\right)$ is strictly decreasing with limit zero. 
(The first two paragraphs of the following proof are due to Harry Pollard, the fourth to the referee. Both Pollard and the referee point out that the relation

$$
\frac{d}{d x}\left[F^{\prime}(x) / F(x)\right]>0
$$

of the fourth paragraph can be deduced from general theorems on completely monotonic functions [5, pp. 144, 145, 167]. I. I. Hirschman, Jr., has observed that the zeros modulo $\pi$ in the interval $0<x<\infty$ of $\int_{x}^{\infty} g(u) \sin u d u$ are monotone decreasing for any $g(u)$ which is completely monotonic on $0<u<\infty)$.

Proof. Let

$$
F(x)=\int_{0}^{\infty} e^{-x u}\left(1+u^{2}\right)^{-1} d u \text { for } x>0
$$

Then

$$
\int_{x}^{a} u^{-1} \sin u d u=\left[F(u) \cos u-F^{\prime}(u) \sin u\right]_{x}^{a}
$$

for $a>0$. To prove this, let $L(x)$ and $R(x)$ denote, respectively, the left and right sides of (1). Since $L(a)=R(a)$, it is sufficient to show that $L^{\prime}(x)=$ $R^{\prime}(x)$ for $x>0$. But this is immediate, for

$$
\begin{aligned}
& L^{\prime}(x)=-x^{-1} \sin x \\
& R^{\prime}(x)=-\sin x\left[F(x)+F^{\prime \prime}(x)\right]=-\sin x \int_{0}^{\infty} e^{-x u} d u .
\end{aligned}
$$

Now taking the limit in (1) as $a \longrightarrow \infty$ gives

$$
-\int_{x}^{\infty} u^{-1} \sin u d u=F(x) \cos x-F^{\prime}(x) \sin x,
$$

for $F(\infty)=F^{\prime}(\infty)=0$.

Since $F(x)>0$ and $F^{\prime}(x)<0$, it follows from (2) that the finite zeros of $\int_{x}^{\infty} u^{-1} \sin u d u$ occur at the points where

$$
\frac{F^{\prime}(x)}{F(x)}=\cot x
$$

Therefore, to complete the proof of the theorem, it is sufficient to show that 
$F^{\prime}(x) / F(x)$ is strictly increasing to zero as $x \rightarrow \infty$.

Employing the usual derivative notation, one has

$$
-(-x)^{n+1} F^{(n)}(x)=x^{n+1} \int_{0}^{\infty} \frac{u^{n} e^{-x u}}{1+u^{2}} d u=\int_{0}^{\infty} \frac{u^{n} e^{-u}}{1+(u / x)^{2}} d u
$$

so that

$$
-(-x)^{n+1} F^{(n)}(x) \rightarrow n ! \text { as } x \longrightarrow \infty
$$

Therefore,

$$
\frac{F^{\prime}(x)}{F(x)}=x^{-1}\left[\frac{x^{2} F^{\prime}(x)}{x F(x)}\right] \rightarrow 0 \text { as } x \rightarrow \infty \text {. }
$$

All that remains to be shown, then, is that $F^{\prime}(x) / F(x)$ is strictly increasing, and this will follow if

$$
\frac{d}{d x}\left[\frac{F^{\prime}(x)}{F(x)}\right]>0
$$

or, equivalently, if

$$
\left[F^{\prime}(x)\right]^{2}-F(x) F^{\prime \prime}(x)<0 \text {. }
$$

Now

$$
F(x)-2 F^{\prime}(x) y+F^{\prime \prime}(x) y^{2}=\int_{0}^{\infty} \frac{e^{-x u}}{1+u^{2}}(1+y u)^{2} d u>0,
$$

so that the discriminant of the quadratic expression in $y$ on the left must be negative. Since this discriminant is $\left[F^{\prime}(x)\right]^{2}-F(x) F^{\prime \prime}(x)$, the proof is complete.

4. The main theorem. Two lemmas are needed.

LEMMA 4.1. If $0<a_{k}<1$ for $k=1, \cdots, n$, and $a_{1}, \cdots, a_{n}, 1$ are linearly independent over the rationals, then, given $\epsilon>0$, there exist odd positive integers $x, I_{1}, \ldots, I_{m}, m \leq n$, and there exist even positive integers $I_{m+1}, \ldots, I_{n}$, such that $0<x a_{k}-I_{k}<\epsilon$ for $k=1, \cdots, n$.

Proof. If $\operatorname{Red} u$ denotes the fractional part of $u$, then it is known that the 
vectors $\left(\operatorname{Red} j a_{1}, \ldots, \operatorname{Red} j a_{n}\right), j=0,1, \cdots$, are dense in the $n$-dimensional unit-cube $[1, \mathrm{p} .83]$. Hence there is a positive integer $j$ such that

$$
\begin{array}{lr}
\frac{1}{2}\left(1-a_{k}\right)<\operatorname{Red} j a_{k}<\min \left(\frac{1-a_{k}+\epsilon}{2}, 1\right) & (k=1, \cdots, m), \\
\frac{1}{2}\left(2-a_{k}\right)<\operatorname{Red} j a_{k}<\min \left(\frac{2-a_{k}+\epsilon}{2}, 1\right) & (k=m+1, \cdots, n) .
\end{array}
$$

The conclusion of the lemma is satisfied by taking

$$
x=2 j+1, I_{k}=2\left(j a_{k}-\operatorname{Red} j a_{k}\right)+1 \text { for } k=1, \cdots, m,
$$

and

$$
I_{k}=2\left(j a_{k}-\operatorname{Red} j a_{k}+1\right) \text { for } k=m+1, \cdots, n \text {. }
$$

Lemma 4.2. Let $\alpha(x)$ be defined as in $2(a)$. If $\beta_{1}, \cdots, \beta_{N}, 1$ are linearly independent over the rationals, then $F(\alpha)>1$.

Proof. Let $P, Q$ be the sets of positive integers $k \leq N$ for which $A_{k}>0$, $A_{k}<0$, respectively. Then

$$
f(x)=\frac{2}{\pi}\left(\sum_{k \in P}+\sum_{k \in Q}\right) A_{k} \operatorname{Si}\left(x \beta_{k}\right) .
$$

By hypothesis, $0<\beta_{k}<1$ for $k=1, \cdots, N$. Therefore, Lemma 4.1, with $\epsilon=1 / 2$, asserts the existence of a positive $x_{0}$ and nonnegative integers $n_{k}$ such that

$$
0<\pi x_{0} \beta_{k}-\left(2 n_{k}+1\right) \pi<\frac{1}{2} \pi \quad \text { for } k \in P
$$

and

$$
0<\pi x_{0} \beta_{k}-2\left(n_{k}+1\right) \pi<\frac{1}{2} \pi \quad \text { for } k \in Q
$$

By Theorem 3.1, $\operatorname{si}\left(\pi x_{0} \beta_{k}\right)>0$ for $k \in P$ and $\operatorname{si}\left(\pi x_{0} \beta_{k}\right)<0$ for $k \in Q$. Recalling that $\sum A_{k}=1$, one obtains that $f\left(\pi x_{0}\right)>1$, which is sufficient. 
Since

$$
\lim _{A \rightarrow \infty} \operatorname{Si}(A x)=\frac{1}{2} \pi \operatorname{sign} x
$$

boundedly, it follows that $F(g) \geq 1$ for every regular Hausdorff kernel.

Let now $\alpha(x)$ be a regular $N$-jump Hausdorff kernel. It will be shown that if $F(\alpha)=1$, then $\beta_{1}, \cdots, \beta_{N}$ are linearly dependent over the rationals, and this will prove:

THEOREM 4.1. If $\alpha(x)$ is defined as in $2(a)$ with $\beta_{1}, \ldots, \beta_{N}$ linearly independent over the rationals, then $F(\alpha)>1$.

Proof. Let $\beta=\left(\beta_{1}, \cdots, \beta_{N}\right)$ and $r=\left(r_{1}, \cdots, r_{N}\right), r_{k}$ rational. Set

$$
|\beta|=\max _{1 \leq k \leq N} \beta_{k},
$$

and let $x$ be a scalar such that $0<x<|\beta|^{-1}$. Let $\Lambda$ be the zero $N$-tuple. The inner product of $N$-tuples $A$ and $B$ is defined in the usual way and is denoted by $(A \mid B)$. Let

$$
\alpha^{x}(t)=1 \text { for } x \beta_{N} \leq t \leq 1
$$

and $a^{x}(t)=\alpha(x t)$ otherwise. Then $\alpha^{x}$ is also a regular $N$-jump Hausdorff kernel, and $F\left(\alpha^{x}\right)=F(\alpha)$.

Suppose now that $F(\alpha)=1$. According to Lemma 4.2, there corresponds to each $x$ in the interval $0<x<|\beta|^{-1}$ an $r_{x} \neq \Lambda$ and a rational number $R_{x}$ such that

$$
\left(x \beta \mid r_{x}\right)=R_{x} .
$$

But the available $r_{x}, R_{x}$ are countable while the permissible $x$ are uncountable. Hence, there is an uncountable set $X$ of $x$ associated with an $r \neq \Lambda$ and a rational $R$. If $x, x^{\prime} \in X$, then

$$
\left(x-x^{\prime}\right)(\beta \mid r)=0 \text {. }
$$

Taking $x \neq x^{\prime}$ gives $(\beta \mid r)=0$; that is, $\beta_{1}, \cdots, \beta_{N}$ are linearly dependent over the rationals.

5. The two-step case. The theorem to be proved is: 
'Т'НЕОВЕм 5.1. If $\alpha(x)$ is a regular two-jump Hausdorff kernel, then $F(\alpha)>1$.

Proof. If $\beta_{1}$ and $\beta_{2}$ are linearly independent over the rationals, then Theorem 4.1 gives the result.

If $\alpha(x)$ is not an increasing function, then either $A_{1}>1$ and $A_{2}<0$ or $A_{1}<0$ and $A_{2}>1$. Suppose that it is the first. Recalling that $A_{1}+A_{2}=1$, one obtains

$$
f(x)=\frac{2}{\pi} \operatorname{Si}\left(x \beta_{1}\right)-\frac{2}{\pi} A_{2}\left[\operatorname{Si}\left(x \beta_{1}\right)-\operatorname{Si}\left(x \beta_{2}\right)\right]
$$

Since $A_{2}<0$, and $\mathrm{Si}(\pi)$ is the absolute maximum of $\mathrm{Si}(x)$, it follows that

$$
f\left(\pi / \beta_{1}\right) \geq \frac{2}{\pi} \operatorname{Si}(\pi)>1
$$

The remaining two-jump kernels are those which are increasing and for which

$$
\frac{\beta_{2}}{\beta_{1}}=\frac{p}{q}
$$

with $p$ and $q$ integral and $(p, q)=1$. If $p$ and $q$ are odd, there is no problem, for then $f\left(\pi q / \beta_{1}\right)>1$. Otherwise, one of $p, q$ is odd and the other even. To treat this situation, the following lemma, whose proof offers no difficulty, is useful:

LemmA 5.1. Let $0<b_{1}<b_{2} \leq 1$. If $I_{1}$ and $I_{2}$ are odd positive integers such that

$$
\left|I_{1} b_{2}-I_{2} b_{1}\right|<\frac{\epsilon}{\pi}\left(b_{1}+b_{2}\right)
$$

then there exists a positive number $x$ such that

$$
\left|x b_{k}-\pi I_{k}\right|<\epsilon \text { for } k=1,2 \text {. }
$$

By Theorem 3.1, the proof of Theorem 5.1 will be complete if a positive $x$ and odd positive integers $I_{1}$ and $I_{2}$ exist such that

$$
\left|x \beta_{k}-\pi I_{k}\right|<1.215 \text { for } k=1,2 \text {. }
$$


By the above lemma, then, one wishes to find odd positive integers $I_{1}=2 i+1$ and $I_{2}=2 j+1$ such that

$$
\left|p I_{1}-q I_{2}\right|=|2 p i-2 q j+p-q|<\frac{1.215}{\pi}(p+q) \text {. }
$$

Since $p$ and $q$ have unlike parity, $p+q \geq 3$. It will therefore be sufficient to find nonnegative integers $i$ and $j$ such that $2 p i-2 q j+p-q=1$.

If $p-q=1$, simply take $i=q$ and $j=p$.

If $p-q \geq 3$, then the Diophantine equation

$$
p i-q j=\frac{1}{2}(1-p+q)
$$

makes sense and, furthermore, has positive solutions $i$ and $j$.

6. Remark. According to Theorem 3.2, the zeros modulo $\pi$ of $\operatorname{si}(x)$ tend to $\pi / 2$. Therefore, the method of proof used in this paper can not be expected to handle all step-function kernels omitted by Theorem 4.1.

\section{REFERENCES}

1. J. F. Koksma, Diophantische Approximationen, Chelsea, New York.

2. Otto Szász, On the Gibbs' phenomenon for Euler means, Acta Sci. Math. Szeged 12 Part B (1950), $107-111$.

3. , Gibbs' phenomenon for Hausdorff means, Trans. Amer. Math. Soc. 69 (1950), 440-456.

4. Tables of Sine, Cosine, and Exponential Integrals, vol. II, Federal Works Agency, Works Progress Administration for the City of New York, 1940.

5. D. V. Widder, The Laplace Transform, Princeton, 1941. 



\section{PACIFIC JOURNAL OF MATHEMATICS}

\section{EDITORS}

\section{R. U. FOEINSON}

University of California

Berkeley 4, California

E. HewitT

University of Washington

Seattle 5 , Washington
P. P. DILWOR TH

California Institute of Technology

Pasadena 4, California

E. F. BECKENBACH

University of California

Los Angeles 24, California

\section{ASSOCIATE EDITORS}

$\begin{array}{llll}\text { H. BUSEMANN } & \text { P. R. HALMOS } & \text { BØRGE JESSEN } & \text { J. J. STOKER } \\ \text { HERBERT FFDERER } & \text { IIEINZ HOPF } & \text { PAUL LÉVY } & \text { E. G. STRAUS } \\ \text { MARSHALL, IIALI } & \text { R. D. JAMES } & \text { GEORGE PÓLYA } & \text { KÖSAKU YOSIDA }\end{array}$

\section{SPONSORS}

UNIVERSITY OF BRITISH COLUMBIA

CALIFORNIA INSTITUTE OF TECHNOLOGY.

UNIVERSITY OF CAIJIFORNIA, BERKELEY

UNIVERSITY OF CAIJIFORNIA, DAVIS

UNIVERSITY OF CALIFORNIA, LOS ANGELES

UNIVERSITY OF CALIFORNI A, SANTA BARBARA

UNIVERSITY OF NEVADA

OREGON STATE COLLEGE

UNIVERSITY OF OREGON

\author{
UNIVERSITY OF SOU TIERN CALIFORNIA \\ STANFORD RESEARCH INSTITUTE \\ STANFORD UNIVERSITY \\ WASHINGTON STATE COLLEGE \\ UNIVERSITY OF WASHINGTON \\ AMERICAN MATHEMATICAL SOCIETY \\ NATIONAL BUREAU OF STANDARDS, \\ INSTITUTE FOR NUMERICAL ANALYSIS
}

Mathematical papers intended for publication in the Pacific Journal of Mathematics should be typewritten (double spaced), and the author should keep a complete copy. Manuscripts may be sent to any of the editors except Robinson, whose term expires with the completion of the present volume; they might also be sent to M.M. Schiffer, Stanford University, Stanford, California, who is succeeding Robinson. All other communications to the editors should be addressed to the managing editor, E. F. Beckenbach, at the address given above.

Authors are entitled to receive 100 free reprints of their published papers and may obtain additional copies at cost.

The Pacific Journal of Mathematics is published quarterly, in March, June, September, and December. The price per volume (4 numbers) is $\$ 8.00$; single issues, $\$ 2.50$. Special price to individual faculty members of supporting institutions and to individual members of the American Mathematical Society: $\$ 4.00$ per volume; single issues, $\$ 1.25$.

Subscriptions, orders for back numbers, and changes of address should be sent to the publishers, University of California Press, Berkeley 4, California.

Printed at Ann Arbor, Michigan. Entered as second class matter at the Post Office, Berkeley, California.

\section{UNIVERSITY OF CALIFORNIA PRESS • BERKELEY AND LOS ANGELES}




\section{Pacific Journal of Mathematics}

\section{Vol. 3, No. 2 \\ April, 1953}

William George Bade, An operational calculus for operators with spectrum

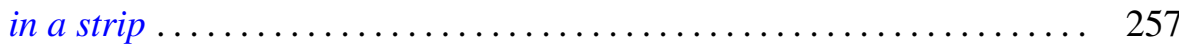

E. F. Beckenbach and Lloyd Kenneth Jackson, Subfunctions of several variables ..................................... 291

David Blackwell, Extension of a renewal theorem ................. 315

L. Carlitz, Some theorems on the Schur derivative ................ 321

Paul Arnold Clement, Generalized convexity and surfaces of negative curvature..................................... 333

Merrill M. Flood, On the Hitchcock distribution problem ............... 369

Watson Bryan Fulks, On the unique determination of solutions of the heat

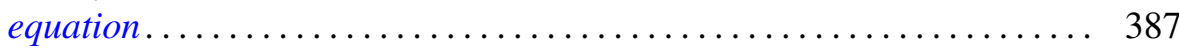

John W. Green, Length and area of a convex curve under affine transformation .................................... 393

William Gustin, An isoperimetric minimax .................. 403

Arthur Eugene Livingston, Some Hausdorff means which exhibit the Gibbs'

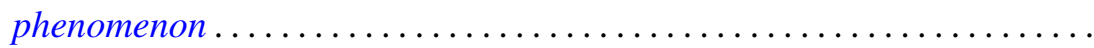

Charles Loewner, On generation of solutions of the biharmonic equation in the plane by conformal mappings ..................... 417

Gábor Szegő, Remark on the preceding paper of Charles Loewner ....... 437

Imanuel Marx and G. Piranian, Lipschitz functions of continuous

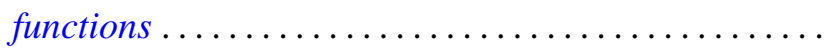

Ting-Kwan Pan, The spherical curvature of a hypersurface in Euclidean space ..

Ruth Lind Potter, On self-adjoint differential equations of second order ...

E. H. Rothe, A note on the Banach spaces of Calkin and Morrey...

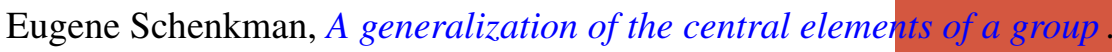

A. Seidenberg, A note on the dimension theory of rings .. . . 